\title{
Picoeukaryote diversity in coastal waters of the Pacific Ocean
}

\author{
Alexandra Z. Worden* \\ Marine Biology and Fisheries Division, Rosenstiel School of Marine and Atmospheric Science, 4600 Rickenbacker Causeway, \\ Miami, Florida 33134, USA
}

\begin{abstract}
The extraordinary molecular phylogenetic diversity of picoeukaryotes and their contributions to marine processes have been highlighted recently. Herein, picoeukaryotic diversity in the coastal Pacific Ocean is characterized for the first time. Close to full length small subunit ribosomal RNA (ssu rRNA) gene amplicons were cloned and sequenced from size fractionated samples $(<2 \mu \mathrm{m})$ taken between September 2000 and October 2001. Sequences belonging to the order Mamiellales were abundant, with Micromonas pusilla-like sequences in all 5 libraries (4 operational taxonomic units, OTUs, at $\geq 99 \%$ sequence similarity), Ostreococcus in 4 (1 OTU) and Bathycoccus in 2 (1 OTU). Phylogenetic reconstruction showed distinct Micromonas clades at this site (although not for other Mamiellales), supporting the idea that the designation M. pusilla harbors cryptic species. In combination with picophytoplankton dynamics previously reported for the same period, the data indicates that picoplanktonic primary production at this site is likely to be dominated by prasinophytes. Furthermore, a Micromonas-clade with no cultured representatives was identified bearing highest identity to Sargasso Sea shotgun clone sequences. Comparison of the Pacific sequences with the shotgun clones showed Ostreococcus and Micromonas at 1 Sargasso site with elevated chlorophyll (chl) levels, but not at other Sargasso sites. Other Pacific clones were primarily Novel Alveolate Group II, which were highly diverse based on OTU analyses. Novel Alveolate Group I, Ciliophora, Cercozoalike and stramenopile sequences were also retrieved. Although picoeukaryotic diversity has been characterized in only 1 other Pacific Ocean sample (equatorial Pacific), most stramenopile and alveolate sequences corresponded to previously identified phylogenetic clades from studies conducted in other oceans and for which no cultured representatives exist.
\end{abstract}

KEY WORDS: Picoeukaryotes · Picophytoplankton · Picoplankton · Diversity $\cdot$ Micromonas pusilla Prasinophytes $\cdot 18 \mathrm{~S}$ rRNA $\cdot$ Small subunit

Resale or republication not permitted without written consent of the publishe

\section{INTRODUCTION}

Although photosynthetic picoeukaryotes have been recognized as important primary producers for more than a decade (Li 1994), they and their heterotrophic counterparts have only recently begun to be more extensively analyzed in terms of population diversity. Over the last several years, studies have demonstrated tremendous molecular phylogenetic diversity among these organisms. The first reports of such broad diversity included studies from the equatorial Pacific Ocean (Moon-van der Staay et al. 2001), the Antarctic Polar Front (Lopez-Garcia et al. 2001), the Mediterranean,
Wedell, and Scotia Seas as well as from the North Atlantic Ocean (Diez et al. 2001) and were based on size-fractionated 18S rRNA gene clone libraries. More recently, similar levels of diversity have been revealed in European coastal waters, and the importance of prasinophytes highlighted in these settings (Guillou et al. 2004, Massana et al. 2004b, Not et al. 2004, Romari \& Vaulot 2004). Furthermore, multiple novel clades within the alveolates and stramenopiles, bearing no cultured representatives, and hence of unknown ecological function, were identified and are now being experimentally investigated (Massana et al. 2004a). The extent of this molecular diversity is also being pur- 
sued in other pelagic marine environments (e.g. Yuan et al. 2004) and freshwater systems (e.g. Richards et al. 2005).

The goal of the present work was to characterize picoeukaryotic communities in Pacific Ocean coastal waters. The mean chlorophyll concentration at the study site (Scripps Pier off La Jolla, California, North American Pacific coast) is $1.58 \mathrm{\mu g} \mathrm{l}^{-1}$, but ranges from as low as $0.02 \mu \mathrm{g} \mathrm{l}^{-1}$ to as high as $300 \mu \mathrm{g} \mathrm{l}^{-1}$, based on results from more than a decade of monitoring (1983 to 1997; J. McGowan pers. comm.). A characteristic feature is an intense bloom of the dinoflagellate Lingulodinium polyedrum, generally starting in the spring and continuing throughout the summer (e.g. Mourino Perez et al. 2003, Worden et al. 2006). Picophytoeukaryotes have been reported to play an important role in primary production here, dominating picophytoplankton carbon production and composing a high percentage of carbon consumed from this size fraction by grazers (Worden et al. 2004). Differences in surfacearea to volume ratios are known to play a role in strategies and competition factors for microbes (Raven 1986), making comparison of similarly sized organisms an important component of ecological studies on aquatic microbes. The sequences reported herein were derived from the smallest eukaryotic size fraction, that of the picoplankton $(<2 \mu \mathrm{m}$ diameter $)$, with most other published reports including sequences derived from fractions ranging from $<1.6$ to $<5 \mu \mathrm{m}$ (or no fractionation). Emphasis was placed on the analysis of photosynthetic picoeukaryotes because of their recognized importance in this system, especially relative to the prokaryotic picophytoplankton.

\section{MATERIALS AND METHODS}

DNA extraction was performed on 11 seawater samples collected from surface waters at the end of the $330 \mathrm{~m}$ long Scripps Pier ( $32^{\circ} 53^{\prime}$ N, $117^{\circ} 15^{\prime} \mathrm{W}$ ), a Pacific Ocean coastal site bound by the California Current. Samples were collected in September and late December 2000, as well as April, July and October 2001, and immediately filtered through $2 \mu \mathrm{m}$ pore size polycarbonate filters (except the September 2000 sample, which was filtered through a $1 \mu \mathrm{m}$ pore size filter), with low vacuum ( 3 pounds per square inch, psi) in Year 2000, and no vacuum in Year 2001. Flow cytometric analysis showed fewer picophytoeukaryote cells in vacuum filtered samples than in gravity filtered samples (Worden unpubl.), indicating that cells may have broken even under low vacuum (hence the change to gravity filtration). The filtrate was immediately filtered onto a $0.45 \mu \mathrm{m}$ pore size Supor filter (Pall Gelman), using 3 psi vacuum, and frozen at $-80^{\circ} \mathrm{C}$ until later processing. Genomic DNA was extracted using the DNeasy Tissue Extraction Kit (Qiagen), as recommended by the manufacturer, with incubation at $55^{\circ} \mathrm{C}$ for $3 \mathrm{~h}$. Water temperature was attained from the Scripps Pier weather observations group.

Gene amplification was accomplished using primers for the eukaryotic ssu rRNA gene (EUK328f: 5'-ACCTGGTTGATCCTGCCAG-3'; EUK329r: 5'-TGATCCTTYGCAGGTTCAC-3') complementary to conserved regions of the $5^{\prime}$ and $3^{\prime}$ termini of the gene (Moon-van der Staay et al. 2000). PCR reactions used $1 \mu \mathrm{l}$ of extracted DNA in a total volume of $50 \mu \mathrm{l}$, with $2.5 \mathrm{U}$ HotStar Taq DNA polymerase (Qiagen), and final concentrations of $1.5 \mathrm{mM} \mathrm{MgCl}_{2}, 200 \mu \mathrm{M}$ each dNTP and $0.5 \mu \mathrm{M}$ each primer. The following PCR conditions were used: $95^{\circ} \mathrm{C}$ for $15 \mathrm{~min}$; 32 cycles at $94^{\circ} \mathrm{C}$ for $1 \mathrm{~min}$, $55^{\circ} \mathrm{C}$ for $2 \mathrm{~min}$ and $72^{\circ} \mathrm{C}$ for $3 \mathrm{~min}$; and a final extension at $72^{\circ} \mathrm{C}$ for $10 \mathrm{~min}$. PCR products were cloned into the pCR2.1 cloning vector (TOPO-TA, Invitrogen) according to the manufacturer's instructions, with approximately 500 clones plated per library. Plasmids were isolated from randomly picked colonies using the Qiaprep Kit (Qiagen) and restricted using 2 enzymes (BST XI and ECO RI, Boehringer-Mannheim) to prescreen for the correct insert.

For the first library (September 2000), 25 plasmids were pre-screened by restriction banding profile differences (using the above enzymes); a subset (17) was then partially sequenced, and 11 plasmids were then selected for complete sequencing with a focus on Ostreococcus. The inserts were sequenced bidirectionally on an ABI Prism 377 or 3100 using vector primers, M13R and M13F, as well as primers internal to the product (502f: 5'-GGAGGGCAAGTCTGGT-3', 551r: TGGCACCAGACTTGCC, $1174 \mathrm{r}$ 5'-CCCGTGTTGAGTCAAA-3', 1084F: 5'-GGAGTATGGTCGCAAGG-3') in order to attain full length coverage of both strands. For all subsequent libraries, 50 plasmids were screened by restriction, a total of 14 banding patterns identified, and a fraction of the clones falling within each of these banding patterns sequenced (as above) for each library. Specifically, within each library, individual patterns represented by more than 4 clones were subsampled and sequenced first with the $502 \mathrm{f}$ primer (27 to $38 \%$ of plasmids with a respective pattern were sequenced per library), those unique to the library were then fully sequenced; for patterns represented by 1 to 4 plasmids all were sequenced. Metazoan-derived sequences (5) were excluded from further sequencing. For each of these 4 libraries, 22 clones were sequenced in part with the internal primer. In total, 79 clones were fully sequenced. Raw sequence data was assembled and edited using the software Sequencher (Gene Codes) or Lasergene (DNAstar). All sequences have been deposited in GenBank 
under Accession Nos. AF525848-AF525879, AY129029AY129069 and DQ369013-DQ369019.

Initial characterization of full length sequences was made by BLAST searching the GenBank nr database (previously 'non-redundant') and used to place the majority of sequences in 4 primary groupings-chlorophytes, stramenopiles, alveolates and Cercozoa. Sequences were also blasted against the trimmed individual reads (downloaded from URL www. venterinstitute.org/sargasso/) from Sargasso Sea shotgun clones (Venter et al. 2004). Operational taxonomic units (OTUs) were assessed with the SeqMan II module in Lasergene 6.1 (DNASTAR) at 4 different identity levels corresponding to $\geq 99,98,97$ and $96 \%$ sequence similarity (note that restriction profiles were not used for OTU analysis). Probable chimeras (Wp1, 05Np2, 30Fp2), based on CHECK-CHIMERA (Cole et al. 2003) and identification by manual alignment, composed primarily of a sequence from one organism, were trimmed to remove the chimeric portion. These sequences were excluded from OTU and phylogenetic analyses, whereas sequences that were only potentially chimeras (30Dp2, Yp3, Bp4), but less clearly so, were included in OTU analyses. Phylogenetic analyses of the prasinophytes were conducted using 2 alignments, one composed of nearly full length ( 1800 bp) gene sequences retrieved from GenBank, the other using a partial region of the gene (526 bp) in order to incorporate environmental sequences which are often less than $600 \mathrm{bp}$ in length. Alignments were generated using ClustalW (Thompson et al. 1994), then manually checked and edited using the software BioEdit (Hall 1999). The alignments were further edited using the Gblocks method (Castresana 2000) to select conserved blocks for phylogenetic analysis (minimum block length $=5$; allowed gap positions $=$ with half) as well as manual elimination of non-homologous positions. Subsequently, $\gamma$-values and transition/transversion for each prasinophyte alignment were estimated independently using 20000 quartet puzzling steps in TREEPUZZLE 5.2 (Schmidt et al. 2002). Phylogenetic analyses were conducted using Phylip 3.62 modules (Felsenstein 2005), with maximum likelihood (ML) methods, in DNAML with global rearrangements and randomized sequence-input order (2 jumbles), as well as distance (DNADIST) and neighbor-joining (NEIGHBOR) methods calculated using the F84 model. $\Gamma$-values were entered as the coefficient of variation $(\mathrm{CV})$ according to requirements for Phylip modules (CV = $1 /\left[(\alpha)^{1 / 2}\right]$; where $\alpha=$ the gamma distribution shape parameter). Support for trees was obtained by bootstrapping 100 data sets.

\section{RESULTS AND DISCUSSION}

These seasonal ssu rDNA libraries yield the first insights into picoeukaryote diversity in Pacific coastal waters. Most clones fell into 1 of 4 general groups, chlorophytes, alveolates, Cercozoa or stramenopiles

Table 1. Classification and operational taxonomic unit (OTU) number for full length $18 \mathrm{~S}$ clones from each of the 5 libraries. Also shown are size fraction and water temperature. Note that the prefix UEPAC has been removed from the clone identification. Classification based on highest identity by BLASTn to the National Center for Biotechnology Information (NCBI) nr database (autumn 2005); alveolates also underwent rough phylogenetic analysis (not shown), confirming group placements. Total OTUs are given at $\geq 96,97,98$, and $99 \%$ identity levels

\begin{tabular}{|c|c|c|c|c|c|c|}
\hline Classification & $\begin{array}{l}\text { Total OTUs } \\
\text { 96/97/98/99 }\end{array}$ & $\begin{array}{c}\text { P1 } \\
6 \text { Sept } 2000\end{array}$ & $\begin{array}{c}\text { P2 } \\
29 \text { Dec } 2000\end{array}$ & $\begin{array}{c}\text { P3 } \\
19 \text { April } 2001\end{array}$ & $\begin{array}{c}\text { P4 } \\
\text { 6 July } 2001\end{array}$ & $\begin{array}{c}\text { P5 } \\
26 \text { Oct } 2001\end{array}$ \\
\hline Prasinophyceae & $3 / 4 / 4 / 6$ & 9 & 4 & 7 & 4 & 7 \\
\hline Bathycoccus & $1 / 1 / 1 / 1$ & 0 & 0 & 1 (Dp3) & 0 & 1 (AEp5) \\
\hline Micromonas & $1 / 2 / 2 / 4$ & $2\left(\mathrm{Zp} 1, \mathrm{Wp} 1^{\mathrm{a}}\right)$ & 1 (30Np2) & 2 (Op3, 40p3) & $4(22 \mathrm{p} 4, \mathrm{Vp} 4,34 \mathrm{p} 4, \mathrm{Sp} 4)$ & 3 (ACp5, AXp5, Mp5) \\
\hline Ostreococcus & $1 / 1 / 1 / 1$ & $\begin{array}{l}7 \text { (CCp1, AAp1, Bp1, } \\
\text { Dp1, LLp1, Ap1, Xp1) }\end{array}$ & $\begin{array}{c}3 \text { (30Gp2, } \\
30 \mathrm{Hp} 2,05 \mathrm{Fp} 2)\end{array}$ & $\begin{array}{c}4 \text { (Np3, Kp3, } \\
\text { Jp3, Gp3) }\end{array}$ & 0 & $\begin{array}{l}4 \text { (Ip5, Jp5, } \\
\text { Alp5, Np5) }\end{array}$ \\
\hline Alveolates & $22 / 23 / 24 / 25$ & 2 & 6 & 7 & 9 & 6 \\
\hline Novel Group I & $4 / 4 / 4 / 4$ & 1 (Cp1) & 0 & 0 & $1(36 p 4)$ & 2 (Qp5, Dp5) \\
\hline Novel Group II & $15 / 15 / 17 / 18$ & 0 & $\begin{array}{c}5 \text { (Fp2, Ap2, } \\
\text { 05Ep2, 30Ep2, } \\
\left.\text { 30Fp2 } 2^{\mathrm{a}}\right)\end{array}$ & $\begin{array}{c}7 \text { (AQp3, 41p3, } \\
\text { APp3, Hp3, Cp3, } \\
\text { Fp3, Ep3) }\end{array}$ & $\begin{array}{c}8(15 \mathrm{p} 4, \mathrm{Lp} 4,43 \mathrm{p} 4 \\
42 \mathrm{p} 4,18 \mathrm{p} 4, \mathrm{Dp} 4 \\
\left.46 \mathrm{p} 4, \mathrm{Bp} 4^{\mathrm{b}}\right)\end{array}$ & 3 (Fp5, APp5, Ep5) \\
\hline Ciliophora & $2 / 2 / 2 / 2$ & 1 (Jp1) & $1\left(05 \mathrm{~Np} 2^{\mathrm{a}}\right)$ & 0 & 0 & 1 (AIp5) \\
\hline Stramenopiles & $7 / 8 / 8 / 9$ & 1 (Dp1) & $\begin{array}{c}3(05 \mathrm{Cp} 2,30 \mathrm{Cp} 2, \\
\left.30 \mathrm{Dp} 2^{\mathrm{b}}\right)\end{array}$ & $1(48 p 3)$ & $3(37 \mathrm{p} 4,45 \mathrm{p} 4, \mathrm{Cp} 4)$ & 3 (Lp5, Op5, Rp5) \\
\hline Haptophyceae & $1 / 1 / 1 / 1$ & 0 & 0 & 0 & $1(47 \mathrm{p} 4)$ & \\
\hline Cercozoa-like & $5 / 5 / 5 / 5$ & 0 & 1 (05Hp2) & 3 (Lp3, Yp3 ${ }^{\text {b }}$, AHp3) & $2(\mathrm{Mp} 4,33 \mathrm{p} 4)$ & 0 \\
\hline Size fraction $(\mu \mathrm{m})$ & & $<1$ & $<2$ & $<2$ & $<2$ & $<2$ \\
\hline Temperature $\left({ }^{\circ} \mathrm{C}\right)$ & & 21.2 & 14.5 & 21.2 & 20.7 & 17.6 \\
\hline
\end{tabular}


(Table 1). The green algae (Chlorophyta) sequences were closely related to cultured prasinophytes (Figs. 1 \& 2). The only other likely phototroph sequence was found in a single library (July 2001) and belonged to the Haptophyta, with highest identity (98\%) to equatorial Pacific clone OLI16108, well-placed within the prymnesiophytes (Moon-van der Staay et al. 2000).

The Prasinophyceae-derived sequences (Fig. 1) all fell within the order Mamiellales. As such, picoprasinophytes appeared to be important at this coastal Pacific Ocean site, since they were the only picoeukaryotic photoautotroph sequences represented throughout the year. Micromonas was present in all 5 libraries, Ostreococcus in 4, and Bathycoccus in 2 (Fig. 1, Table 1). Time-series data, analyzed using the same size fractionation criteria as the libraries presented herein, showed that eukaryotes were responsible for $67 \%$ of the picophytoplankton biomass over the course of the year, despite being less abundant than Synechococcus and roughly equal to Prochlorococcus in abundance (Worden et al. 2004). In addition, picoeukaryotic growth rates $\left(0.71\right.$ to $\left.1.29 \mathrm{~d}^{-1}\right)$ were consistently higher than that of Synechococcus (0.52 to $0.86 \mathrm{~d}^{-1}$ ) and Prochlorococcus (0.09 to $0.48 \mathrm{~d}^{-1}$ ). Overall, picophytoeukaryotes were responsible on average for $75 \%$ of picoplanktonic primary production and $79 \%$ of the carbon consumed by higher trophic levels (Worden et al. 2004). In combination with sequence data, this suggests that prasinophytes may be responsible for a large fraction of picophytoplanktonic production at this site, as well as a source of carbon to higher trophic levels, although confirmation by quantitative approaches is necessary.

Without quantitative data it is unclear which of the identified genera was most abundant or potentially responsible for a greater degree of primary production at this site. Population dynamics are complicated by the nearby influence of strong currents and tidal cycles, and mean population cell size of picophytoeukaryotes, monitored on a weekly basis, also varied frequently, with measurable changes on an almost weekly basis between August 2000 and February 2002 (Worden et al. 2004). A rough analysis, based on these 67 data points, taking the extremes in average cell diameter as reflecting either a primarily Micromonas dominated population (when $\geq 1.8 \mu \mathrm{m}$ ) or a primarily Ostreococcus dominated community (when $\leq 1.4 \mu \mathrm{m}$ ), indicates 14 dates on which Micromonas potentially dominated and 6 dates on which Ostreococcus dominated. However, most often the community average size fell within these extremes, i.e. between 1.4 and $1.8 \mu \mathrm{m}$. Ostreococcus blooms have been observed at a monitoring site farther north off the California Coast $\left(33.55^{\circ} \mathrm{N}, 118.40^{\circ} \mathrm{W}\right)$, but over much of the year it was low in abundance (Countway \& Caron 2006). Furthermore, the genus Ostreococcus can grow extremely rapidly, as shown in a French lagoon (Fouilland et al. 2004), and was abundant in these Pacific libraries and many other clone libraries (see e.g. Guillou et al. 2004). However, studies employing both clone libraries and fluorescence in situ hybridization (FISH) reveal a large discrepancy between clone library abundance and organism abundance (via FISH). For example, in the English Channel, Ostreococcus dominated clone libraries (Vaulot et al. 2002, Romari \& Vaulot 2004), but Micromonas pusilla dominated in terms of actual organism abundance by FISH analyses (Not et al. 2004). M. pusilla has also been shown to dominate the picophytoeukaryotes in polar waters based on cell abundance (Not et al. 2005). Thus, an important task for understanding the factors controlling picophytoeukaryote dynamics will be to resolve the respective activities and controls of each genus and ecotypes within. The complete genome sequences of $O$. tauri (Derelle et al. in press) as well as others under way (e.g. genomes of 2 Micromonas strains) should aid in developing hypotheses on niche differentiation among these organisms.

With respect to 'within genus' diversity, Micromonas is most notable, with 5 clades being identified based on 2 criteria: (1) bootstrap support by both phylogenetic methods employed in analyses of full length sequences (Fig. 1), and (2) inclusion of sequences from 2 or more sources (e.g. 2 different clone libraries, or 2 different culture isolations). It should be noted that there is a single described species, M. pusilla, within the genus Micromonas. Most cultured strains are listed as being M. pusilla, including those which fall in separate

Fig. 1. ssu rDNA phylogeny of the pico-prasinophytes identified in Pacific coastal waters inferred by neighbor-joining (NJ) and maximum likelihood (ML) methods of 1640 positions from an alignment of available full length sequences. ML tree is shown with corresponding significant $(<50)$ bootstrap values (percentage of 100 replicates) on internal branches obtained by NJ and ML methods (in order NJ-distance/ML) ('-' indicates not significant). Colored boldface sequences represent different sampling dates in present study: light blue, 6 September 2000; dark blue, 29 December 2000; pink, 19 April 2001; green, 6 July 2001; purple, 26 October 2001. For Micromonas clades, a decimal system is used, incorporating results from previous studies (Guillou et al. 2004, Slapeta et al. 2006) and the present study (GuillouClade.SlapetaClade.SignificantClades from this analysis); thick blue arrow indicates uncultured Micromonas clade (B._.4). Sequences from other culture-independent studies are in black boldface. Black italicized sequences are from cultured Mamiellales; red italicized sequences from non-Mamiellales organisms (both Pyramimonadales and Streptophyta). gt: genotype 
Color Key

Sept. 2000 Pacific

Dec. 2000 Pacific

April 2001 Pacific

July 2001 Pacific

October 2001 Pacific

Other environmental

Cultured Mamiellales

Cultured non-Mamiellales

0.1
Micromonas

$53 / 100$

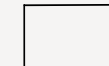

CS222 (AY955010)

CS170 (AY955009)

CCMP1195 (AY954993)

NEPCC29 (AY955012)

UEPAC30Np2 (AF525860)

RA000412.97 (AY425319)

CCMP1764 (AY954998)

CCMP494 (AY95500 8)

- UEPACACp 5 (AF525876)

UEPACZp1 (AF525856)

CCMP492 (AY955006)

CCMP493 (AY955007)

CCMP489 (AJ010408)

CCMP1723 (AY954997)

CCMP488 (AY955001)

CCMP489 (AY955002)

MBIC10095 (AY955011)

A.BC. 1

A.A. 2

$50 / 97$

94/95

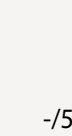

97

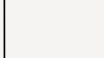

|CCMP1646 gt A (AY954995)

UEPAC22p4 (AF525868)

RCC434 (AY 425316)

CCMP1646 gt B (AY954996)

- UEPACVp4 (AF525870)

$-/ 54$

- RA000412.37 (AY425317)

UEPACAXp5 (AF525878)

$-/ 100$ LCCMP2099 gt A (AY954999)

$89 / 90 \longrightarrow$ CCMP2099 gt B (AY955000)

84/- UEPAC34p4 (AF525871)

93/100 84/- UEPACSP4 (AF525869)

$100 / 100$ [BL000921.10 (AY425318)

CCMP490 genOYP3 (AF525866)

CCMP49enotype A (AY955003)

CCMP490 genotype $B$ (AY955004)

CCMP1545 (AY954994)

- UEPAC40p3 (AF525867)

CCMP490 (AY425320)

CCMP491 (AY955005)

UEPACMp5 (AF525874)

B.E. 3

L Mantoniella antarctica (AB017128)

\begin{tabular}{|l|r}
\hline Mamiella \& & Mantoniella antarctica (AB017 \\
Mantoniella squamata (X73999)
\end{tabular}

Mantoniella

Mamiella sp. Shizugawa (AB017129)

\begin{tabular}{|l|l}
\hline Ostreococcus & $68 / 69$ y UEPACNp3 (AF52586 \\
\hline UEPACIP5 (AF525872)
\end{tabular}

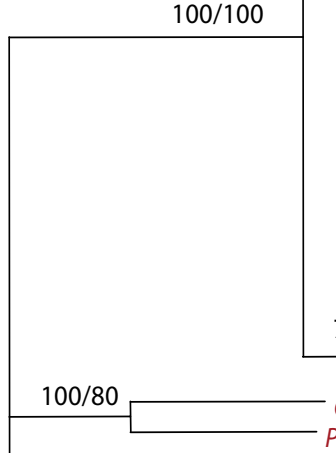

$771-$

- UEPACKp3 (AF525863)

- UEPACJp3 (AF525862)

- UEPAC30Hp2 (AF525859)

- UEPAC05Fp2 (AF525857)

$56 / 58$

- RCC344 (AY 425307)

$100 / 100$

- RCC356 clone 1 (AY425308)

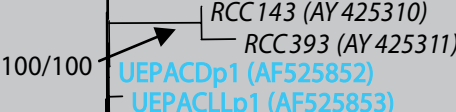

- UEPACGp3 (AF525861)

MBIC10636 (AB058376)

RA010421.39 (AY425309)

CAI27230.00018 (DQ007077)

UEPACJp5 (AF525873)

UEPACXP1 (AF525855)

- UEPACALP5 (AF525877)

59/51 UEPAC30Gp2 (AF525858)

- UEPACNp5 (AF525875)

100/100 - Ostreococcus CCE9901

RA000412.150 (AY425312)

Ostreococcus tauri (AY329635)

69/63 Ostreococcus RCC501 (AY425313)

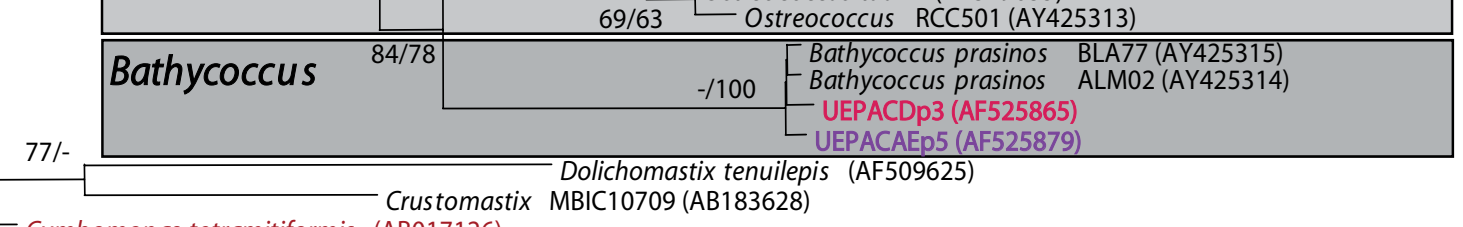

Cymbomonas tetramitiformis (AB017126)

Pyramimonas olivacea (AB017122) 


\section{Color Key}

Sept. 2000 Pacific

Dec. 2000 Pacific

April 2001 Pacific

July 2001 Pacific

October 2001 Pacific

Other environmental

Cultured Mamiellales

Cultured non-Mamiellales

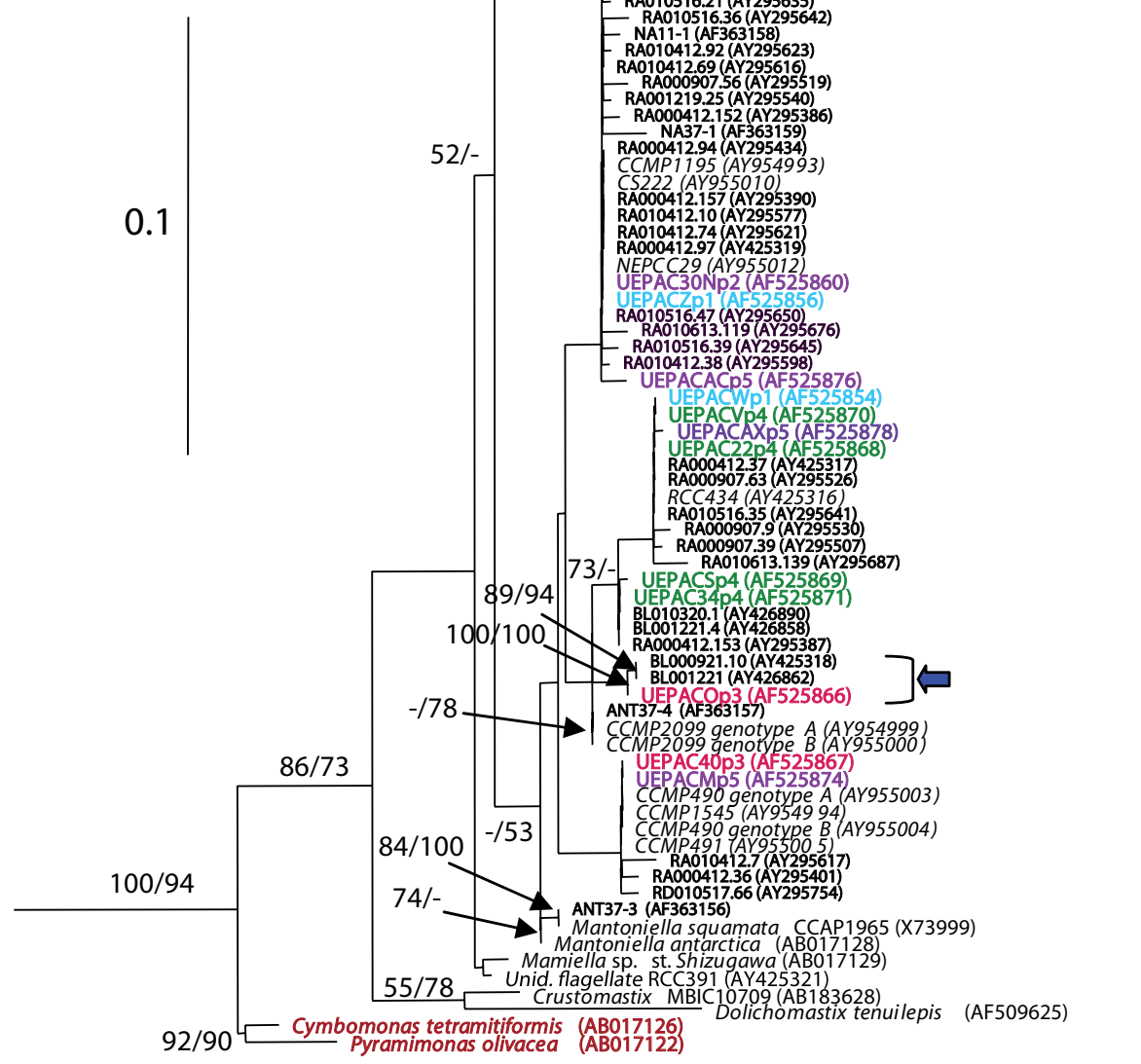

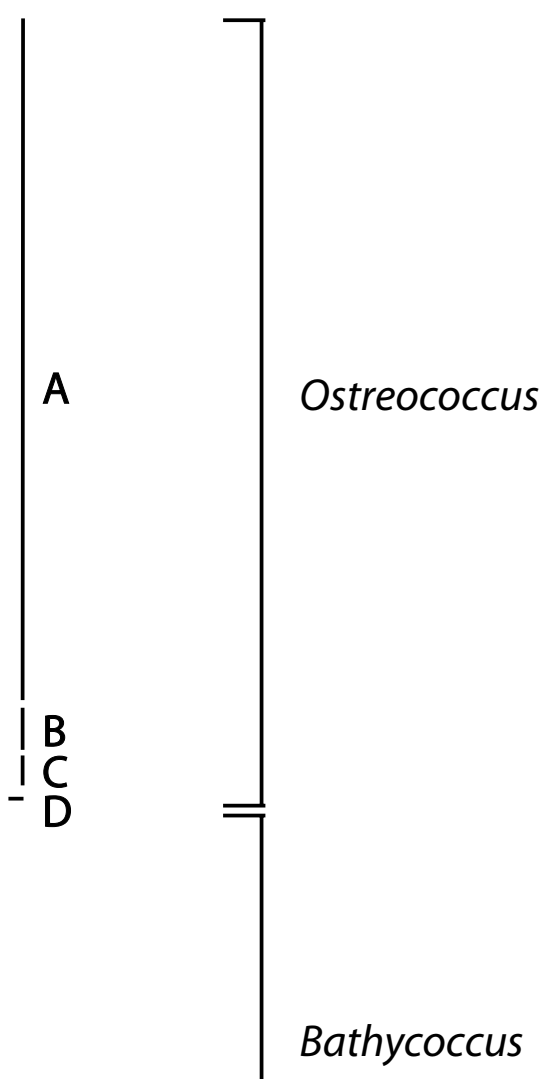

A.ABC. 12

B.E. 34

Micromonas 
Fig. 2. ssu rDNA phylogenetic tree inferred from homologous positions of an alignment of 133 prasinophyte partial sequences using NJ and ML methods (see 'Materials and methods'). The NJ-distance tree is shown with corresponding significant $(<50)$ bootstrap values (percentage of 100 replicates) on the internal branches obtained from NJ and ML methods (in the order NJ-distance/ML) or a '-' if not significant. Colored bold sequences are from this study, as defined in Fig. 1. Ostreococcus clades (A-D) are the same as in Guillou et al. (2004). Micromonas clades utilize a decimal system incorporating results from previous studies (Guillou et al. 2004, Slapeta et al. 2006) and here (GuillouClade.SlapetaClade.SignificantClades herein from full length analysis, i.e. Fig. 1); in this partial tree some clades identified using full length sequences (Fig. 1) are collapsed. Thick blue arrow indicates the uncultured Micromonas clade (B._.4). Sequences from other culture-independent studies are shown in boldface. Black italicized sequences are from cultured Mamiellales; red italicized are from non-Mamiellales prasinophytes. Outgroup (not shown) was formed by Streptophyta representatives

clades here and in other analyses. Previous reports have identified between 3 (Guillou et al. 2004) and 5 (Slapeta et al. 2006) Micromonas clades, assigning letters to each. The clade identifications in these studies do not correspond to each other, in part because Slapeta et al. (2006) focused on a few full length sequences but included phylogenetic analysis of other genes. These supported the 18S phylogeny, but with greater evolutionary distances (in the other markers), rendering a more refined view of divergence within the studied cultures. The results of Guillou et al. (2004) were based on analysis of partial sequences, allowing environmental sequences to be evaluated. In the present paper, these clade identifiers are combined in a decimal system (GuillouClade.SlapetaClade.SignificantClades herein from the full length tree) in order to maintain the information from these previous studies (Guillou et al. 2004, Slapeta et al. 2006) while allowing the current data to be discussed. Here, as in Guillou et al. (2004), Clades B and C of Slapeta et al. (2006) collapsed into a single clade, Clade A.BC.1. This is potentially due to addition of full length environmental sequences from the Pacific coast and English Channel, which were absent from the Slapeta et al. (2006) analysis. Clades A.BC.1 and B.E.3 (includes UEPACWp1 in Fig. 2 only because the sequence end was chimeric, see 'Materials and methods') were represented in most libraries, with B.E.3 containing the only Micromonas phylotype found in July (Fig. 1) although the extent of library coverage must be kept in mind. Clade A.ABC.12 (Fig. 2), contained the most cultured and environmental sequences. This clade was previously reported (Guillou et al. 2004) as being composed of cultured and environmental sequences, but with environmental sequences only from the English Channel and Atlantic Ocean. The results herein revise that view by including Pacific sequences (Fig. 2). Interestingly, Clade B._.4 (identified here for the first time) was solely composed of environmental sequences (Figs. 1 \& 2 ). Sequences belonging to this clade were also present in Sargasso Sea shotgun clone data (Venter et al. 2004, see later in discussion), forming the only Micromonas sequence-type in that data. The lack of Clade B._.4 representatives in culture collections may result from the (typically) high-nutrient amendments used for isolation inducing selection of other Micromonas ecotypes, and concentration of culturing efforts in coastal waters. The 2 Micromonas isolates available for the same Sargasso Sea region (M. pusilla CCMP488 and M. pusilla CCMP489) both fall within Clade A.A.2, which, in terms of available full length sequences, is composed only of cultured isolates and no environmental sequences. Overall, these findings support those of Slapeta et al. (2006), who concluded that the designation $M$. pusilla harbors cryptic species.

In contrast, all Pacific Ostreococcus sequences fell into a single OTU at $\geq 99 \%$ sequence identity. The phylogenetic analyses herein, and previously reported (Guillou et al. 2004) show several bootstrap supported Ostreococcus clades (Fig. 2). It should be noted that the position of RCC143 and RCC393 is unusual in the full length analysis (Fig. 1) and is more typical in the partial analysis (Fig. 2). Here the Pacific sequences and many other environmental clones fell within a single clade (Ostreococcus Clade A), despite inclusion of sequences from marine locations worldwide (Fig. 2). Rodriguez et al. (2005) identified members of this clade as being surface, high-light adapted isolates, agreeing with the surface origins of the sequences in the present study. Environmental Bathycoccus sequences also fell within a single OTU at the $99 \%$ level; however, limited clone representation may also have contributed to the low population complexity observed.

Sargasso Sea shotgun clones (Venter et al. 2004) were used to compare the Pacific clones to sequences from non-PCR-amplified libraries. Moreover, the shotgun clone sequences were used to compare the Pacific coastal sequences to open ocean gyre-derived sequences from a different ocean basin (Atlantic) to further assess phylotype geographical distributions, in addition to comparisons with sequences from published 18S-clone libraries. Shotgun clones are advantageous because they avoid PCR biases, although still not rendering organism abundance information due to cloning biases and differences in operon numbers between species. Both Micromonas and Ostreococcus sequences were detected, using the Pacific sequences, at Sargasso Stn $3\left(32^{\circ} 09.51^{\prime} \mathrm{N}, 64^{\circ} 00.61^{\prime} \mathrm{W}\right)$. Prasino- 
phytes are generally considered more coastal in distribution, since they are generally more abundant in coastal areas (e.g. Guillou et al. 2004, Not et al. 2005). Furthermore, the sole pico-size fractionated 18S-clone library from open ocean waters (i.e. the equatorial Pacific) was dominated by prymnesiophytes (Moonvan der Staay et al. 2000). Prasinophytes have been detected previously in low abundance at Hydrostation $\mathrm{S}\left(32^{\circ} 10.00^{\prime} \mathrm{N}, 64^{\circ} 30.00^{\prime} \mathrm{W}\right)$, located near Bermuda on the slope rise, by a combination of HPLC and electron microscopy (Anderson et al. 1996). An HPLC timeseries at the 'Bermuda Atlantic Time Series' (BATS) site also detected prasinophytes, again at low concentrations (Goericke 1998). Micromonas 18S sequences from the Sargasso Sea shotgun clone data (reads UBADJ67TF, UBAED60TR) had 100 and 99\% identity to BL000921.10 and UEPACOp3, respectively, members of the uncultured Micromonas-clade (Clade B._.4). Micromonas sequences have been recovered from North Atlantic waters previously $\left(59^{\circ} 30^{\prime} \mathrm{N}\right.$, $21^{\circ} 8^{\prime} \mathrm{W}$ and $59^{\circ} 34^{\prime} \mathrm{N}, 21^{\circ} 3^{\prime} \mathrm{W}$ ) significantly north of the Gyre. Interestingly, the $18 \mathrm{~S}$ partial sequence clones NA11- and NA37-1 have 99\% identity to UEPAC30Np2 and RA000412.97, falling in Clade A.ABC.12 (collapsed Clades A.BC.1 and A.A.2) in the partial tree, and not with the uncultured Micromonas-clade (Fig. 2). With respect to Ostreococcus sequences, UAALP06TF (again Stn 3) had $99 \%$ identity to RCC143 and RCC393 (Clade B, Fig. 2) and lower identity (98\%) to several Clade A environmental sequences (e.g. RA010412.39, RA000412.150 and UEPACJp5); 2 other Stn 3 clones (UAAT664TF and UBAL343TR) had 100\% identity to RCC143 and $99 \%$ to UEPAC sequences from a number of libraries (e.g. UEPACAp1, UEPAC30Gp2 and UEPACJp5). The strains RCC143 and RCC393, isolated from $120 \mathrm{~m}$ (Tropical Atlantic) and $90 \mathrm{~m}$ (Mediterranean), respectively, have been characterized as being low-light adapted (Rodriguez et al. 2005). Stn 3 was considerably north of BATS, and previous work in this area concluded that BATS is '...near the southern extent of the area affected by winter mixing' (Lipschultz et al. 2002). Thus, although the Sargasso sequences with high identity to RCC143 and RCC393 were derived from surface waters, the water column was presumably deeply-mixing given the time of year (February) that samples were collected. This raises the possibility that such cultures are not low-light adapted per se, as described based on light-regulated growth experiments (Rodriguez et al. 2005), but are better adapted to life in open-ocean conditions, which include periods of time in deeply-mixing waters. This hypothesis would explain grouping of surface retrieved clones with cultures identified as low-light adapted. In the Sargasso data set no Bathycoccus-like sequences were found. Nor were prasinophyte $18 \mathrm{~S}$ sequences found at other stations, indicating that Stn 3 sequences were not carryover contaminants, e.g. from other locations. Samples 5 (Hydrostation S) and 2 (a mixture of material from 2 stations: Stns 13: $31^{\circ}$ $32.10^{\prime} \mathrm{N}, 63^{\circ} 35.70^{\prime} \mathrm{W}$ and $11: 31^{\circ} 10.50^{\prime} \mathrm{N}, 64^{\circ} 19.46^{\prime} \mathrm{W}$ ), both contained haptophyte-like sequences closer to Emiliania huxleyi and Prymnesium parvum or Chrysochromulina-like, respectively, than to UEPAC47p4. Regarding other photosynthetic eukaryotes, dinoflagellate-like (e.g. Gymnodinium mikimotoi-like) sequences appeared at Hydrostation S, but the analysis herein identified few others (except as above). It should be noted that Sample 5 (Hydrostation S) was from the 3 to $20 \mu \mathrm{m}$ size fraction as opposed to the $<0.8 \mu \mathrm{m}$ size fraction of most other samples, including Hydrostation S Sample 7 ( $<0.8 \mu \mathrm{m}$ fraction). Relative to other sites, Stn 3 showed elevated chl levels based on Modis-Aqua data from the same time period, and almost 2-fold higher in situ relative fluorescence at the surface (Venter et al. 2004). Given their absence from other stations, these Micromonas and Ostreococcus sequences in 'unamplified' data could be related to the elevated chl conditions. Thus, in such scenarios these organisms could potentially contribute significantly to open ocean primary production, although this requires confirmation by quantitative methods.

While the primary goal of this study was to characterize the photoautotrophic picoeukaryotes in coastal Pacific waters, a significant number of sequences from clades of unknown ecological function were retrieved. In general these were distinct from cultured organisms but many had high identity to recently discovered environmental sequences within the stramenopiles and alveolates (e.g. Diez et al. 2001, Moon van der Staay et al. 2001, Lopez-Garcia et al. 2001).

Among the 11 fully sequenced stramenopile clones, 8 OTUs were found at $\geq 98 \%$ identity (Table 1 ). The selection of identity level is still controversial with respect to ecological or physiological significance, with cultures with as high as $>99.5 \%$ identity having been considered different species (e.g. Medlin et al. 1994). In the case of uncultured groups, the relevant $18 \mathrm{~S}$ rDNA identity level for differentiation remains difficult to ascertain and consequently somewhat arbitrary. In this study, even at the $\geq 96 \%$ identity level, the number of stramenopile OTUs (7) was relatively high; 2 OTUs were composed of multiple sequences from different dates, i.e. not merely a second clone from the same library, indicating some level of temporal stability of the particular OTU. The sequences had high identities (97 to $99 \%$ ) to environmental clones from (e.g.) the North Atlantic (Diez et al. 2001, Countway et al. 2005), the North Sea, the Mediterranean and the English Channel (Massana et al. 2004b). These results support those of Massana et al. (2004a), who reported several 
environmental groups for which no cultured representative exists, and (based on phylogenetic clades) identified 12 MAST (novel marine stramenopiles) groups. In the present study, 2 sequences fell within the Dictyochophyceae, including UEPACDp1, with $97 \%$ identity to the phototroph Florenciella parvula (Eikrem et al. 2004), and UEPAC30Dp2 with $93 \%$ identity to the uncultured clone BL001221.35. UEPAC05Cp2 was closest (97 to $99 \%$ ) to several environmental sequences within MAST-4, a group reported to be bacterivorous heterotrophic flagellates (Massana et al. 2002), and had only $92 \%$ identity to the closest cultured organism, Paraphysomonas imperforata (AF109323). UEPAC30Cp2, UEPAC45p4 and UEPACLp5 were closest to environmental sequences in what has been characterized as MAST-7 and UEPACCp4 to MAST-4, having low identity (92 to $94 \%$ ) to the closest cultured organism, Thraustochytrium multirudimentale. Two sequences (UEPAC48p3 and UEPAC37p4), related to Chrysophyceae, bore $94 \%$ identity to Mallomonas strains, with higher identity $(96 \%)$ to only 1 other sequence, E222, an environmental clone from the permanently anoxic basin of the Caribbean Sea (Stoeck et al. 2003). Lastly, UEPACOp5 and UEPACRp5 fell within MAST-3, with low identity (92\%) to the closest cultured organism, Rhizidiomyces apophysatus, a proposed relative of the oomycetes (Hausner et al. 2000). As Massana et al. (2004a) have emphasized, the high identities to environmentally derived sequences, but relatively low identities to cultured organisms suggests there are many pico-stramenopiles about which nothing is known in terms of functional ecology.

The 30 fully sequenced alveolate clones fell into 3 broad groups (see e.g. Moreira \& Lopez-Garcia 2002), the 'Novel Alveolate Group I' (4), 'Novel Alveolate Group II' (23) and the Ciliophora (3). No Group II-like sequences were retrieved in the first library (P1, September 2000). However, these sequences were abundant on other dates, forming 17 OTUs at the $98 \%$ level (Table 1). The first library was built from the $<1 \mu \mathrm{m}$ size fraction; thus, their absence possibly reflects size exclusion of Group II alveolates (if $>1 \mu \mathrm{m}$ ). Of interest is the similarity of the putatively heterotrophic community (those sequences not falling into clearly photoautotrophic/mixotrophic groups and otherwise undescribed) found through all seasons in this study as well as other reports on both surface and deep ocean waters. Some clones had highest identity to Amoebophrya species or environmental clones grouped with the Amoebophrya. Amoebophrya are known to parasitize dinoflagellates (Yih \& Coats 2000). The ecological roles of the Amoebophrya-like Novel Group II sequences are still unclear but, if phylogenetic placement is an indication of a parasitic lifestyle, it is interesting that the majority of Amoebophrya-like se- quences were retrieved from the April (UEPACFp3, UEPACEp3) and July (UEPAC18p4, UEPACDp4, UEPAC46p4) libraries. At the site under study, a series of annual blooms occur, particularly of the dinoflagellate Lingulodinium polyedrum, starting in the spring (e.g. April, Fandino et al. 2001) and continuing throughout the summer (e.g. September, Worden et al. 2006). This raises the possibility of linked temporal dynamics of these populations, which must be explored keeping in mind the potential size exclusion effects highlighted above. It should be noted that the Group I and II alveolates are composed of a broad group of phylotypes as initially defined (Lopez-Garcia et al. 2001, Moreira \& Lopez-Garcia 2002), and have undergone a more refined phylogenetic analysis based on the many sequences deposited over the past few years (Groisillier et al. 2006). Lastly, the 3 Ciliophora sequences were all Strombidium-like, bearing highest identity to uncultured, environmentally derived sequences. No picoplanktonic ciliates have been described to date and it has been suggested that such sequences are likely to be from larger ciliates broken during filtration.

As in other recent studies, cercozoan-like sequences (5) were recovered from 3 libraries (Table 1). The April sequences were close (97 to $98 \%$ identity) to environmental clones BL010320.34 and BL001221.32 from 2 different times of the year in Mediterranean waters, and NA37-5 from North Atlantic waters. UEPACYp3 appeared to be a chimera, with the majority of the sequence being derived from UEPACLp3/UEPACAHp3-like sequences, but the final portion being metazoan prior to trimming. Cercozoa-like sequences from December and July libraries had lower identities to sequences in the GenBank nr database. Portions of UEPAC $05 \mathrm{Hp} 2$ bear $92 \%$ identity to both cercozoan (AF411282, an uncultured cercozoan, and AJ457811, Gromia oviformis) and haplosploridian (AY449715, a known parasite of soft prawns, i.e. Pandulus spp.) sequences, the latter from a disputed phylogenetic position, either being placed within the Cercozoa (Cavalier-Smith \& Chao 2003) or a sister group (Reece et al. 2004). Identity over the complete gene sequence (via ClustalW) was highest to the haplosporidian (84\% versus $82 \%$ to the others), a very low value; nevertheless, this sequence does not appear to be chimeric. Finally, the July library yielded 2 additional unusual sequences, UEPACMp4 being closest to cultured Cercozoa (e.g. $93 \%$ to WHOI LI1-14 and Allas sp. JJP2003) and UEPAC33p4 closest to chlorarchniophytes (e.g. $94 \%$ to Chlorarachnion reptans CCMP 238). These 2 clones had low identity to each other (84\%).

With respect to the Sargasso data set, sequences similar to some UEPAC alveolates were identified. The highest similarity of UXANB87TR was $98 \%$ to 
UEPACCp1, a Group I alveolate. Likewise, UXAAG88TR (Sample 5) was 99\% identical to UEPAC36p4 and other environmental clones (for example M2-D06, which, according to the GenBank entry, is from 'microeukaryotes below the chemocline of the anoxic Mariager Fjord, Denmark') and 98\% to P6X4-2 (a protistan sequence from 'seawater batch cultures contaminated with crude oil'). These widely varying environments suggest a high degree of physiological plasticity of the sequence-associated organism. Amoebophrya-like Pacific sequences (e.g. UEPAC18p4 and UEPAC05Ap2) bore 94 to $95 \%$ identity to SXABP33TR (Sample 2), UEAIJ17TF (Sample 4), UEAN726TR (Sample 4). In this analysis, hits with high identity (e.g. $\geq 97 \%$ ) were not seen between the Pacific Novel Alveolate Group II sequences and the Sargasso data set, nor were Pacific stramenopile or Cercozoa-like sequences seen. Given the restrictive size fraction of the Sargasso samples, it is unclear whether a particular missing phylotype was in very low abundance (and not cloned), not present in the environment, or simply excluded from the $<0.8 \mu \mathrm{m}$ size fraction, especially as different cell structure alters the passage of some protists more than others. What can be said is that some Micromonas, Ostreococcus and Novel Alveolate Group I sequences were highly similar in the 2 data sets, suggesting a cosmopolitan nature of these protists.

Seasonal clone libraries are valuable in rendering targets for hypothesis development and testing. Debates continue regarding limitations to evolutionary diversification of marine protists based on lack of geographic boundaries (e.g. Finlay 2002, Slapeta et al. 2006). At this juncture, it seems advisable to amend the 3 dimensional view (and discussion) of ocean boundaries with the 4th dimension, time (both short and long time frames) and associated variations (e.g. nutrient availability), which contributes to boundaries between populations and consequent diversification. From the results of this study, prasinophytes appear to be important members of the productive picophotoautotrophic community in these coastal Pacific waters. The diversity within the prasinophytes, and especially within Micromonas populations, indicates a high degree of niche differentiation and evolutionary success among these populations. Much less can be said regarding the diverse assemblage of stramenopiles and alveolates observed. The lack of knowledge with respect to ecological roles of the organisms 'attached' to the reported sequences is tremendous. It is critical that efforts be intensified to bring these organisms into culture and to develop approaches to study their abundance, real-time behavior and activities in the field so that their roles in ocean biogeochemical cycles can be fully appreciated.
Acknowledgements. B. Palenik, R. A. Chastain and A. A. Yayanos provided laboratory space and equipment for clone library construction. I also thank R. Gausling for helpful discussions and methodological input, the CSUPERB Microchemical Core Facility at San Diego State University for their excellent sequencing work, Y. Van de Peer and S. Rombauts for use of bioinformatics resources, as well as F. Not and C. Beardsley for helpful comments on the manuscript. Very helpful corrections and comments were also provided by 4 anonymous reviewers. This work was supported by an NSF Microbial Biology Fellowship 0074392, and a Gordon and Betty Moore Foundation Young Investigator award.

\section{LITERATURE CITED}

Anderson RA, Bidigare RR, Keller MD, Latasa M (1996) A comparison of HPLC pigment signatures and electron microscopic observations for oligotrophic waters of the North Atlantic and Pacific Oceans. Deep-Sea Res II 43: $517-537$

Castresana J (2000) Selection of conserved blocks from multiple alignments for their use in phylogenetic analysis. Mol Biol Evol 17:540-552

Cavalier-Smith T, Chao E (2003) Phylogeny and classification of phylum Cercozoa (Protozoa). Protist 154:341-358

Cole JR, Chai B, Marsh TL, Farris RJ, Wang Q, Kulam SA (2003) The ribosomal database project (RDP-II): previewing a new autoaligner that allows regular updates and the new prokaryotic taxonomy. Nucleic Acids Res 31:442-443

Countway PD, Caron DA (2006) Abundance and distribution of Ostreococcus sp. in the San Pedro Channel, California, as revealed by quantitative PCR. Appl Environ Microbiol 72:2496-2506

Countway PD, Gast R, Savai P, Caron DA (2005) Protistan diversity estimates based on 18S rDNA from seawater incubations in the western North Atlantic. J Eukaryot Microbiol 52:95-106

Derelle E, Ferraz C, Rombauts S, Rouzé P and 20 others (in press) Genome analysis of the smallest free-living eukaryote Ostreococcus tauri unveils many unique features. Proc Natl Acad Sci

Diez B, Pedros-Alio C, Massana R (2001) Genetic diversity of eukaryotic picoplankton in different oceanic regions by small-subunit rRNA gene cloning and sequencing. Appl Environ Microbiol 67:2932-2941

Eikrem W, Romari K, Latasa M, Le Gall F, Throndsen J, Vaulot D (2004) Florenciella parvula gen. et sp. nov. (Dictyochophyceae, Heterokontophyta), a small flagellate isolated from the English Channel. Phycologia 43:658-668

Fandino LB, Riemann L, Steward GF, Long RA, Azam F (2001) Variations in bacterial community structure during a dinoflagellate bloom analyzed by DGGE and 16S rDNA sequencing. Aquat Microb Ecol 23:119-130

Felsenstein J (2005) PHYLIP (Phylogeny Inference Package) version 3.6. Distributed by the author. Department of Genome Sciences, University of Washington, Seattle, WA

Finlay BJ (2002) Global dispersal of free-living microbial eukaryote species. Science 296:1061-1063

Fouilland E, Descolas-Gros C, Courties C, Collos Y, Vaquer A, Gasc A (2004) Productivity and growth of a natural population of the smallest free-living eukyryote under nitrogen deficiency and sufficiency. Microb Ecol 48:103-110

Goericke R (1998) Response of phytoplankton community structure and taxon-specific growth rates to seasonally varying forcing in the Sargasso Sea off Bermuda. Limnol Oceaongr 43:921-935 
Groisillier A, Massana R, Valentin K, Vaulot D, Guillou L (2006) Genetic diversity and habitats of two enigmatic marine alveolate lineages. Aquat Microb Ecol 42:277-291

Guillou L, Eikrem W, Chretiennot-Dinet M, Le Gall F, Massana R, Romari K, Pedros-Alio C, Vaulot D (2004) Diversity of picoplanktonic prasinophytes assessed by direct nuclear ssu rDNA sequencing of environmental samples and novel isolates retrieved from oceanic and coastal marine ecosystems. Protist 155:193-214

Hall TA (1999) BioEdit: a user-friendly biological sequence alignment editor and analysis program for Windows 95/98/NT. Nucleic Acids Symp Ser 41:95-98

Hausner G, Belkhiri A, Klassen G (2000) Phylogenetic analysis of the small subunit ribosomal RNA gene of the hyphochytrid Rhizidiomyces apophysatus. Can J Bot 78: $124-128$

Li WKW (1994) Primary production of prochlorophytes, cyanobacteria, and eukaryotic ultraplankton: measurements from flow cytometric sorting. Limnol Oceanogr 39:169-175

Lipschultz F, Bates NR, Carlson CA, Hansell DA (2002) New production in the Sargasso Sea: history and current status. Global Biogeochem Cycles 16:10.1029/2000GB001319

Lopez-Garcia P, Moreira D, Rodriguez-Valera F (2001) Diversity of free-living prokaryotes from a deep-sea site at the Antarctic Polar Front. FEMS Microbiol Ecol 36:193-202

Massana R, Guillou L, Diez B, Pedros-Alio C (2002) Unveiling the organisms behind novel eukaryotic ribosomal DNA sequences from the ocean. Appl Environ Microbiol 68:4554-4558

Massana R, Castresana J, Balague V, Guillou L, Romari K, Groisillier A, Valentin K, Pedros-Alio C (2004a) Phylogenetic and ecological analysis of novel marine stramenopiles. Appl Environ Microbiol 70:3528-3534

Massana R, Balague V, Guillou L, Pedros-Alio C (2004b) Picoeukaryotic diversity in an oligotrophic coastal site studied by molecular and culturing approaches. FEMS Microbiol Ecol 50:231-243

Medlin LK, Lange M, Baumann MEM (1994) Genetic differences among three colony-forming species of Phaeocystis: further evidence for the phylogeny of the Prymnesiophyta. Phycologia 33:199-212

Moon-van der Staay S, van der Staay G, Guillou L, Vaulot D, Claustre H, Medlin L (2000) Abundance and diversity of prymnesiophytes in the picoplankton community from the equatorial Pacific Ocean inferred from 18S rDNA sequences. Limnol Oceanogr 45:98-109

Moon-van der Staay SY, DeWachter R, Vaulot D (2001) Oceanic 18S rDNA sequences from picoplankton reveal unsuspected eukaryotic diversity. Nature 409:607-610

Moreira D, Lopez-Garcia P (2002) The molecular ecology of microbial eukaryotes unveils a hidden world. Trends Microbiol 10:31-38

Mourino Perez RR, Worden AZ, Azam F (2003) Growth of Vibrio cholerae O1 in red tide waters off California. Appl Environ Microbiol 69:6923-6931

Not F, Latasa M, Marie D, Cariou T, Vaulot D, Simon N (2004) A single species, Micromonas pusilla (Prasinophyceae), dominates the eukaryotic picoplankton in the western English Channel. Appl Environ Microbiol 70:4064-4072

Editorial responsibility: Fereidoun Rassoulzadegan, Villefrance-sur-Mer, France
Not F, Massana R, Latasa M, Marie D and 5 others (2005) Late summer community composition and abundance of photosynthetic picoeukaryotes in Norwegian and Barents Seas. Limnol Oceanogr 50:1677-1686

Raven JA (1986) Physiological consequences of extremely small size for autotrophic organisms in the sea. In: Platt T, Li WKW (eds) Photosynthetic picoplankton. Can J Fish Aquat Sci, p 1-70

Reece KS, Siddall ME, Stokes NA, Burreson EM (2004) Molecular phylogeny of the Haplosporidia based on two independent gene sequences. J Parasitol 90:1111-1122

Richards T, Vepritskiy A, Gouliamova D, Nierzwicki-Bauer S (2005) The molecular diversity of freshwater picoeukaryotes from an oligotrophic lake reveals diverse, distinctive and globally dispersed lineages. Environ Microbiol 7: $1413-1425$

Rodriguez F, Derelle E, Guillou L, Le Gall F, Vaulot D, Moreau $\mathrm{H}$ (2005) Ecotype diversity in the marine picoeukaryote Ostreococcus (Chlorophyta, Prasinophyceae). Environ Microbiol 7:853-859

Romari K, Vaulot D (2004) Composition and temporal variability of picoeukaryote communities at a coastal site of the English Channel from 18S rDNA sequences. Limnol Oceanogr 49:784-798

Schmidt H, Strimmer K, Vingron M, von Haeseler A (2002) TREE-PUZZLE: maximum likelihood phylogenetic analysis using quartets and parallel computing. Bioinformatics 18:502-504

Slapeta J, Lopez-Garcia P, Moreira D (2006) Global dispersal and ancient cryptic species in the smallest marine eukaryotes. Mol Biol Evol 23:23-29

Stoeck T, Taylor G, Epstein S (2003) Novel eukaryotes from the permanently anoxic Cariaco Basin (Caribbean sea). Appl Environ Microbiol 69:5656-5663

Thompson JD, Higgins DG, Gibson TJ (1994) CLUSTALW: improving the sensitivity of progressive multiple sequence alignment through sequence weighting, position-specific gap penalties and weight matrix choice. Nucleic Acids Res 22:4673-4680

Vaulot D, Romari K, Not F (2002) Are autotrophs less diverse than heterotrophs in marine picoplankton? Trends Microbiol 10:266-267

Venter J, Remington K, Heidelberg J, Halpern A and 19 others (2004) Environmental genome shotgun sequencing of the Sargasso Sea. Science 304:66-74

Worden AZ, Nolan JK, Palenik B (2004) Assessing the dynamics and ecology of marine picophytoplankton: the importance of the eukaryotic component. Limnol Oceanogr 49: 168-179

Worden AZ, Seidel M, Smriga S, Wick A, Malfatti F, Bartlett D, Azam F (2006) Trophic regulation of Vibrio cholerae in coastal marine waters. Environ Microbiol 8:21-29

Yih W, Coats D (2000) Infection of Gymnodinium sanguineum by the dinoflagellate Amoebophrya sp.: effect of nutrient environment on parasite generation time, reproduction, and infectivity. J Eukaryot Microbiol 47:504-510

Yuan J, Chen MY, Shao P, Zhou H, Chen YQ, Qu LH (2004) Genetic diversity of small eukaryotes from the coastal waters of Nansha Islands in China. FEMS Microbiol Lett 240:163-170

Submitted: January 17, 2006; Accepted: March 20, 2006

Proofs received from author(s): June 14, 2006 